\title{
Estrogen Deficiency Stimulates B Lymphopoiesis in Mouse Bone Marrow
}

\author{
Toshihide Masuzawa, ${ }^{\star \ddagger}$ Chisato Miyaura, ${ }^{\star}$ Yoshiko Onoe, ${ }^{\star \ddagger}$ Kenichiro Kusano, ${ }^{\star}$ Hiroaki Ohta, ${ }^{\ddagger}$ Shiro Nozawa, ${ }^{\prime}$ \\ and Tatsuo Suda* \\ *Department of Biochemistry, School of Dentistry, Showa University, 1-5-8 Hatanodai, Shinagawa-ku, Tokyo 142, Japan; and \\ ${ }^{\ddagger}$ Department of Obstetrics and Gynecology, School of Medicine, Keio University, 35 Shinanomachi, Shinjuku-ku, Tokyo 160, Japan
}

\begin{abstract}
We have found that an estrogen deficiency causes a marked increase in bone marrow cells. To examine the effect of estrogen on hemopoiesis, we characterized the increased population of bone marrow cells after ovariectomy (OVX). In OVX mice, the percentage of myeloid cells and granulocytes was decreased, whereas that of B220-positive B lymphocytes was selectively increased 2-4 wk after surgery. The total number of myeloid cells and granulocytes did not change appreciably, but that of B220-positive cells was greatly increased by OVX. When OVX mice were treated with estrogen, the increased $B$ lymphopoiesis returned to normal. B220-positive cells were classified into two subpopu-

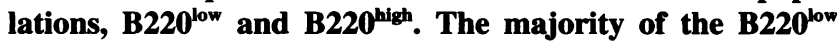
cells were negative for the IgM $\mu$ chain, whereas most of the ${\mathrm{B} 220^{\text {high }}}$ cells were $\mu$-positive. OVX selectively increased the precursors of B lymphocytes identified by B220 ${ }^{\text {low. }} \boldsymbol{\mu}$ negative phenotype, suggesting that an estrogen deficiency stimulates accumulation of B lymphocyte precursors. When bone marrow-derived stromal cells (ST2) were pretreated with estrogen then co-cultured with bone marrow cells in the presence of estrogen, the stromal cell-dependent B lymphopoiesis was greatly inhibited. The present study suggests that estrogen plays an important role in the regulation of $B$ lymphocyte development in mouse bone marrow. (J. Clin. Invest. 1994. 94:1090-1097.) Key words: ovariectomy • hemopoiesis • B lymphocytes • estrogen • stromal cells
\end{abstract}

\section{Introduction}

An estrogen deficiency, caused by either menopause or removal of the ovaries, results in a marked bone loss by increased osteoclastic bone resorption. The pathologic bone loss in this condition can be restored by estrogen replacement therapy, but the mechanism underlying it is not known. Recent studies have established a close relationship between bone remodeling and hemopoiesis in bone marrow $(1,2)$. This suggests that the role of estrogen in hemopoiesis is somehow related to the modulation of bone remodeling by this steroid.

It is known that bone marrow stromal cells support the

Address correspondence to Tatsuo Suda, Department of Biochemistry, School of Dentistry, Showa University, 1-5-8 Hatanodai, Shinagawaku, Tokyo 142, Japan.

Received for publication 16 February 1994 and in revised form 1 June 1994.

J. Clin. Invest.

(c) The American Society for Clinical Investigation, Inc.

0021-9738/94/09/1090/08 $\$ 2.00$

Volume 94, September 1994, 1090-1097 process of growth and differentiation of various hemopoietic cells of the myeloid and lymphoid lineages (3-5). Soluble factors produced by stromal cells, such as IL-6, IL-7, IL-11, and macrophage colony-stimulating factor (M-CSF), ${ }^{1}$ support the proliferation and differentiation of hematopoietic cells. In addition, various cell adhesion molecules for cell-cell and cellmatrix interactions are thought to be involved in the process of hemopoiesis supported by bone marrow stromal cells (6-9). The microenvironment for hemopoiesis in bone marrow also plays an important role in bone remodeling. It is believed that osteoclast progenitors are of hemopoietic origin, and they are recruited from bone marrow. Osteoclast progenitors then proliferate and differentiate into multinucleated osteoclasts in the bone marrow microenvironment supported by stromal cells (10). We have shown that both soluble factors (for example $\mathbf{M}$ CSF) and adhesion molecules produced by stromal cells are indispensable for osteoclast differentiation $(2,10-12)$.

Recent studies on the role of estrogen in osteoclastic bone resorption have focused upon the involvement of at least two cytokines, IL-1 and IL-6. Pacifici et al. (13) have reported that estrogen inhibits IL-1 secretion by peripheral blood monocytes and that an estrogen deficiency allows monocytes to secrete more IL-1. IL-1 is a potent inducer of osteoclastic bone resorption and macrophages have estrogen receptors. On the other hand, Girasole et al. (14) have shown that IL-6 is overproduced by bone marrow stromal cells during an estrogen deficiency. Several lines of evidence have shown that IL-6 is involved in osteoclast differentiation and activation (15-17). These findings suggest that estrogen regulates microenvironment for hemopoiesis in bone marrow by modulating the production of several cytokines, which in turn affect bone remodeling. However, little is known about the role of estrogen in hemopoiesis.

It has been reported that estrogen controls the growth and differentiation of $\mathrm{T}$ lymphocytes in thymus (18). An estrogen deficiency, caused by ovariectomy, results in an increase in the size of the thymus. Conversely, administration of estrogen to normal animals causes atrophy of the thymus. Medina et al. (19) have reported that the number of B lymphocyte precursors is specifically reduced in the bone marrow of normal pregnant mice and that estrogen selectively reduces $B$ lymphocyte precursors when given to normal female mice. This suggests that sex steroids are involved in $\mathrm{B}$ as well as $\mathrm{T}$ lymphopoiesis.

While investigating the role of estrogen in hemopoiesis and bone remodeling, we found that an estrogen deficiency induced by ovariectomy caused a marked increase in bone marrow cells. The stimulation of hemopoiesis after ovariectomy was due to the specific accumulation of precursors of $B$ lymphocytes in the bone marrow. In addition, treatment with estrogen greatly suppressed B lymphopoiesis both in vitro and in vivo. The

1. Abbreviations used in this paper: M-CSF, macrophage colony-stimulating factor; OVX, ovariectomy. 
present study provides evidence that B lymphopoiesis is regulated by estrogen in bone marrow.

\section{Methods}

Animals. 8-wk-old female ddY mice were obtained from Shizuoka Laboratories Animal Center (Shizuoka, Japan). Mice were sham-operated or ovariectomized (OVX). Some OVX mice were treated with estrogen by implanting a slow-releasing pellet of $17 \beta$-estradiol (10 $\mu \mathrm{g}$; Innovative Research of America, Toledo, $\mathrm{OH})$, immediately after surgery. Mice were fed a normal diet $(1.15 \%$ calcium, $0.88 \%$ phosphorous; Oriental Yeast Co. Ltd., Tokyo, Japan) and sacrificed 2, 4, or 8 wk after surgery. Thereafter, uteri were removed and weighed. The right and left tibiae were removed and separated from soft tissues to prepare bone marrow cells. Spleen and peripheral blood mononuclear cells were obtained from 8-wk-old female ddY mice.

Cell preparation. Bone marrow cells were prepared from the right and left tibiae by flushing out the bone marrow with $\mathrm{Ca}^{2+}$ - and $\mathrm{Mg}^{2+}$. free PBS [PBS(-)] using a syringe with a 27-gauge needle. The cells were centrifuged and resuspended in $2 \mathrm{ml}$ of ammonium chloride-Tris buffer to lyse red blood cells. The cell suspension was washed with PBS(-) three times, and resuspended in $1 \mathrm{ml}$ of PBS(-) containing $1 \%$ BSA. Red blood cells in the spleen cells were also lysed as described above, and a suspension of spleen cells was prepared. Peripheral blood mononuclear cells were separated using Ficoll-Conray solution for mouse lymphocytes (M-SMF; Japan Immuno Research Labo. Co., Ltd., Gunma, Japan).

Antibodies. The following antibodies were used as lineage markers for bone marrow cells. FITC-conjugated B220/CD45R (RA3-6B2) and FITC-conjugated Gr-1 (RB6-8C5) purchased from PharMingen (San Diego, CA) were markers for B lymphocytes and granulocytes, respectively $(20,21)$. Mac-1 (M1/70) purchased from Boehringer Mannheim Biochemica (Indianapolis, IN) was a marker for myeloid cells (22). F4/80 purchased from Serotec (Oxford, England) was a marker for macrophages. FITC-conjugated Thy1.2 (TS) was purchased from Seikagaku Corp. (Tokyo, Japan). Over $84 \%$ of the thymocytes prepared from a ddY mouse were positive for the anti-Thy1.2 antibody (data not shown). TER-119, a gift from Dr. T. Kina, Kyoto University, was an erythroid lineage marker (23). Phycoerythrin (PE)-labeled anti- $\mu$ chain IgM was purchased from PharMingen and used for two-color flow cytometry with anti-B220.

Immunofluorescence analysis. Bone marrow cells $\left(1 \times 10^{6}\right)$ were incubated for $30 \mathrm{~min}$ on ice with FITC-conjugated B220, Gr-1 or Thy 1.2, washed twice, and resuspended in PBS(-) containing 1\% BSA. For Mac-1, F4/80 and TER-119, cells were incubated for $30 \mathrm{~min}$ on ice with each antibody, washed twice, and incubated for $30 \mathrm{~min}$ on ice with respective FITC-labeled second antibodies. The negative controls were stained with only second antibodies. Stained cells were analyzed on a flow cytometer (Cyto ACE-150; Japan Spectroscopic Co. Ltd., Tokyo, Japan). Spleen and peripheral blood mononuclear cells were incubated with FITC-conjugated B220 and analyzed with a flow cytometer as described for the analysis of bone marrow cells.

Co-culture of bone marrow cells and stromal cells (ST2). Bone marrow cells and the stromal cell line ST2 were co-cultured by the method of Nishikawa et al. (24). The medium for the co-culture system was phenol red-free RPMI1640 (GIBCO BRL, Gaithersburg, MD) supplemented with $5 \%$ calf serum, $5 \times 10^{-5} \mathrm{M}$ 2-mercaptoethanol, 100 $\mu \mathrm{g} / \mathrm{ml}$ of streptomycin, and $100 \mathrm{U} / \mathrm{ml}$ of penicillin (Meiji Seika Co. Ltd., Tokyo, Japan). Nucleated bone marrow cells $\left(9 \times 10^{5}\right.$ per $75 \mathrm{~cm}^{2}$ flask) prepared from normal mice were cultured in $20 \mathrm{ml}$ of growth medium on the ST2 cell layer, which had been precultured for $7 \mathrm{~d}$. Under these conditions, B cells were selectively grown on the ST2 layer as reported by Nishikawa et al. (24). The medium was changed every 3-4 d. After culture for $14 \mathrm{~d}$, bone marrow cells grown on the ST2 layer were collected by gentle pipetting and counted. They were then incubated with B220 or Mac-1 antibody, and analyzed with a flow cytometer under the same conditions as described above.
Measurement of serum 17 $\beta$-estradiol. Sera collected from five mice in each group were pooled, and $1 \mathrm{ml}$ of the pooled serum was extracted with diethylether. The extracted lipids were applied to HPLC (CAPCELL PAK $\mathrm{NH}_{2}$; Shiseido Corp. Tokyo, Japan) equilibrated with $20 \%$ ethanol in $n$-hexane to separate $17 \beta$-estradiol from estrone and estriol. The fractions containing $17 \beta$-estradiol on HPLC were collected and pooled, and the level of $17 \beta$-estradiol was determined by RIA. The recovery of $17 \beta$-estradiol in the whole process of this assay was $\sim 70 \%$, and the detection limit was $2.5 \mathrm{pg} / \mathrm{ml}$.

Statistical analysis. Data are expressed as mean \pm SEM. The statistical significance of the differences between the sham and the OVX group was determined by Student's $t$ test.

\section{Results}

Effects of OVX on hemopoiesis in mouse bone marrow. Fig. 1 shows the time course of change in uterine weight and the number of nucleated cells in bone marrow after OVX. At 2 wk after OVX, the uterine weight strikingly decreased (Fig. $1 \mathrm{~A}$ ). This indicated that the mice were in estrogen deficiency. Concomitantly, OVX caused a significant increase in nucleated cells in bone marrow in tibiae. The OVX-induced stimulation of hemopoiesis in bone marrow was retained for at least $4 \mathrm{wk}$, and returned to normal at $8 \mathrm{wk}$. The serum level of $17 \beta$-estradiol was decreased at 2 wk after OVX (sham: $17.8 \mathrm{pg} / \mathrm{ml}$; OVX: $7.8 \mathrm{pg} / \mathrm{ml}$ ), and the decreased level was retained until 8 wk after operation. The population of the stimulated hemopoietic cells in OVX mice was characterized by means of immunofluorescence and determined by flow cytometry. Table I compares the percentages of positive cells for the respective lineage markers between the sham-operated and OVX mice 2 wk after operation. The percentages of Mac-1- and Gr-1-positive cells were decreased, whereas that of B220-positive cells was selectively increased. Other lineage cells in bone marrow expressing F4/ 80 , TER 119 or Thy-1.2 were not changed appreciably by OVX. The percentages of respective lineage markers of bone marrow cells in sham-operated mice were all the same as those in agematched control mice (data not shown).

Fig. 2 shows the time course of changes in the population of Mac-1-, Gr-1-, and B220-positive cells after operation. The percentages of Mac-1- and Gr-1-positive cells decreased 2-4 wk after OVX (Figs. 2, $C$ and $E$ ). In contrast, B220-positive cells significantly increased 2-4 wk after OVX, and gradually returned to the control level at 8 wk (Fig. $2 A$ ). Because OVX increased the number of nucleated bone marrow cells, the absolute number of each population expressing respective lineage markers was calculated. As shown in Table I and Figs. 2, D and $F$, the absolute number of Mac-1- and Gr-1-positive cells was not changed after OVX. In contrast, the number of B220positive cells per tibia increased twofold compared with that in sham-operated mice (Table I, Fig. $2 B$ ). All the changes in marrow hemopoiesis induced by OVX returned to normal at $8 \mathrm{wk}$ after operation. These results indicate that an estrogen deficiency selectively stimulates B lymphopoiesis in mouse bone marrow.

$B$ lymphocyte precursors are selectively accumulated in bone marrow in OVX mice. It is not known whether the elevation of B lymphopoiesis in OVX mice can be reversed by estrogen replacement. It is also unknown which subpopulation of $B$ lymphocytes is preferentially affected by OVX. To address the first issue, OVX mice were given a slow-release pellet of $17 \beta$ estradiol $(10 \mu \mathrm{g} / \mathrm{head})$ by implantation immediately after surgery. Fig. 3 shows the pattern of expression of B220-, Mac-1-, 

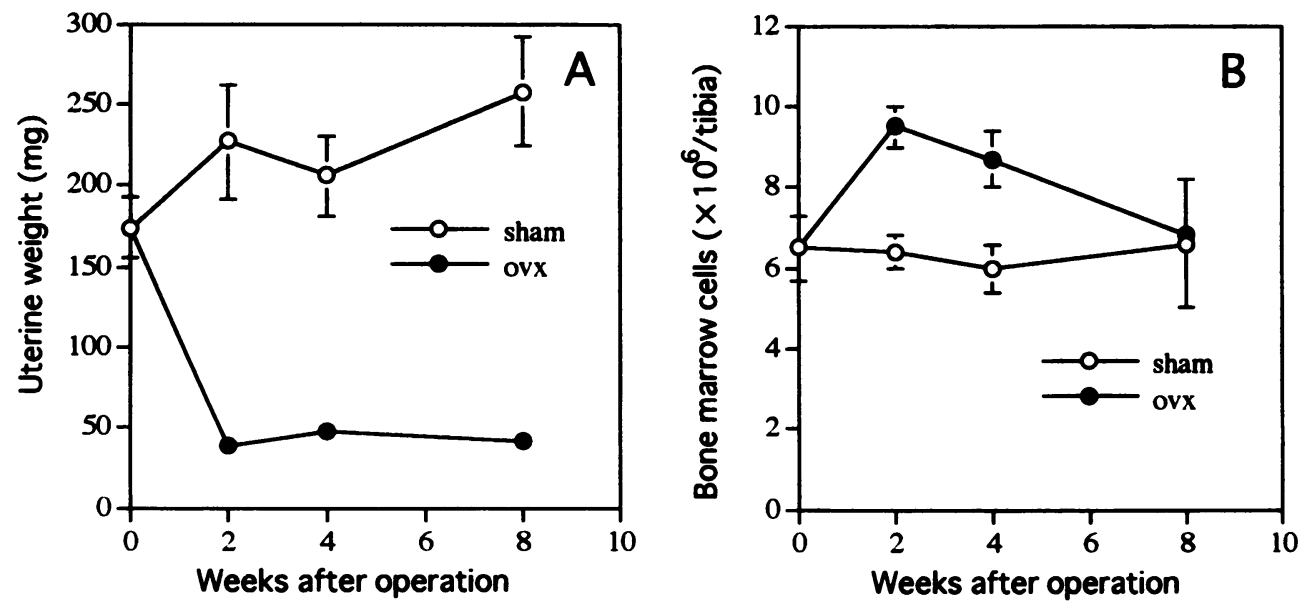

Figure 1. Time course of changes in the uterine weight and number of bone marrow cells after ovariectomy (OVX). (A) Uterine weight: uterine weight in shamoperated $(0)$ or OVX $(\bullet)$ mice was measured $0,2,4$, and 8 wk after operation. $(B)$ Number of bone marrow cells: the number of bone marrow cells collected from the right and left tibiae of sham-operated $(0)$ and OVX (•) mice was calculated. Data are expressed as the means \pm SEM of $8-19$ animals.

and Gr-1-positive cells in sham-operated mice, OVX mice, or OVX mice that received estrogen. OVX decreased the percentages of Mac-1- and Gr-1-positive cells 2 wk after surgery. The proportion of Mac-1- and Gr-1-positive cells did not decrease in OVX mice supplemented with estrogen. In contrast, B220positive B lymphocytes increased after OVX. In sham-operated mice, B220-positive cells were separated into two subpopulations, peak I (B220 low $)$ and peak II (B220 high) (Fig. 3). Peak I was weakly stained with anti-B220 antibody, whereas peak II was intensely stained. This is consistent with the previous observation reported by Hardy et al. (25). In OVX mice, most of the B220-positive cells appeared as peak I. When OVX mice were treated with estrogen, the pattern of B220-positive cells was normal, and the number of B220-positive cells also returned to normal.

To examine the stage of differentiation of B220-positive cells in bone marrow, the pattern of B220-positive cells in bone marrow was compared with those in spleen and peripheral blood

Table I. Effects of Ovariectomy on the Expression of Lineage Markers in Murine Bone Marrow

\begin{tabular}{|c|c|c|c|c|}
\hline & \multicolumn{2}{|c|}{ Percentage of positive cells } & \multicolumn{2}{|c|}{$\begin{array}{l}\text { Total number of positive } \\
\text { cells }\left(\times 10^{6} / \mathrm{tibia}\right)\end{array}$} \\
\hline & Sham & ovx & Sham & ovx \\
\hline & $\%$ & $\%$ & & \\
\hline B220 & $32.4 \pm 1.1$ & $45.6 \pm 1.7 *$ & $2.4 \pm 0.2$ & $4.2 \pm 0.3 *$ \\
\hline Mac-1 & $64.6 \pm 1.9$ & $55.0 \pm 1.8^{\ddagger}$ & $4.7 \pm 0.4$ & $4.9 \pm 0.2$ \\
\hline Gr-1 & $65.1 \pm 1.9$ & $49.3 \pm 2.1^{*}$ & $4.7 \pm 0.4$ & $4.5 \pm 0.3$ \\
\hline $\mathrm{F} 4 / 80$ & $7.2 \pm 1.4$ & $8.3 \pm 1.3$ & $0.5 \pm 0.0$ & $0.8 \pm 0.1$ \\
\hline TER119 & $11.9 \pm 0.9$ & $9.5 \pm 1.1$ & $0.9 \pm 0.1$ & $1.0 \pm 0.1$ \\
\hline Thy-1.2 & $7.7 \pm 0.7$ & $7.0 \pm 0.8$ & $0.6 \pm 0.1$ & $0.7 \pm 0.1$ \\
\hline
\end{tabular}

Bone marrow cells were collected from sham and ovariectomized (OVX) mice $2 \mathrm{wk}$ after operation, and the total number of nucleated cells was counted. The expression of lineage markers was analyzed by flow cytometry after staining the bone marrow cells with each monoclonal antibody. The percentage of positive cells was calculated. The number of positive cells per tibia was calculated from the total number of bone marrow cells and the percentage of positive cells. Significantly different from sham mice: ${ }^{*} P<0.001$; ${ }^{\ddagger} P<0.01$. Data are expressed as the means \pm SEM of $8-19$ animals. in normal mice. Although B220-positive cells consisted of peak I and peak II in bone marrow, they appeared only in peak II in the spleen and peripheral blood (data not shown). This suggests that peak II of B220-positive cells mostly consists of mature B lymphocytes which are localized preferentially in peripheral tissues. Fig. 4 shows a two-color analysis of bone marrow cells with B220 and the $\mu$ chain of IgM in sham-operated and OVX mice 2 wk after surgery. In sham-operated mice, most of the B $220^{\text {high }}$ cells were $\mu$-positive $\left(\mathrm{B} 220^{\text {high }} \cdot \mu^{+}\right)$, and the majority of the B220 $0^{\text {low }}$ cells were negative for the $\mu$ chain $\left(\mathrm{B} 220^{\text {low }} \cdot \mu^{-}\right)$. The population of $\mathrm{B} 220^{\mathrm{low}} \cdot \mu$-negative cells was selectively increased by OVX (Fig. $4 B$ ). These results indicate that estrogen deficiency selectively increases accumulation of $B$ lymphocyte precursors in murine bone marrow.

Estrogen suppresses B lymphopoiesis in vivo and in vitro. To evaluate the effects of estrogen on the growth and differentiation of $B$ lymphocytes, normal female mice were given a pellet of $17 \beta$-estradiol $(10 \mu \mathrm{g})$ and $\mathrm{B}$ lymphopoiesis in the bone marrow was compared with that in untreated mice on day 7. Estrogen caused an increase in uterine weight on day 7 (control, $170 \pm 15 \mathrm{mg}[n=4]$; estrogen, $198 \pm 21 \mathrm{mg}[n=4])$. Also, the estrogen strikingly decreased both peaks of B220-positive cells in the bone marrow (Fig. 5). In contrast, Mac-1- and Gr-1positive cells were not affected by estrogen (data not shown). This indicates that estrogen selectively modulates B lymphopoiesis in the bone marrow.

Finally, we examined the effects of estrogen on the growth and differentiation of $\mathrm{B}$ cells in vitro. Bone marrow cells and bone marrow-derived stromal cells (ST2) were co-cultured according to the method of Nishikawa et al. (24). In this coculture system, precursors of B lymphocytes were selectively grown and differentiated into mature B cells on the ST2 cell layers by day 14 . When ST2 cells were first incubated with $10^{-10}-10^{-8} \mathrm{M} 17 \beta$-estradiol, then co-cultured with bone marrow cells in the presence of the same dose of the steroid, the generation of B220-positive B lymphocytes was strikingly suppressed (Fig. 6). In the control culture without estrogen, B220positive cells were more abundant than Mac-1-positive cells. Estrogen selectively suppressed the population of B220-positive B lymphocytes, but not that of Mac-1-positive myeloid cells.

\section{Discussion}

This study revealed for the first time that estrogen deficiency stimulates B lymphopoiesis in bone marrow. OVX caused a 

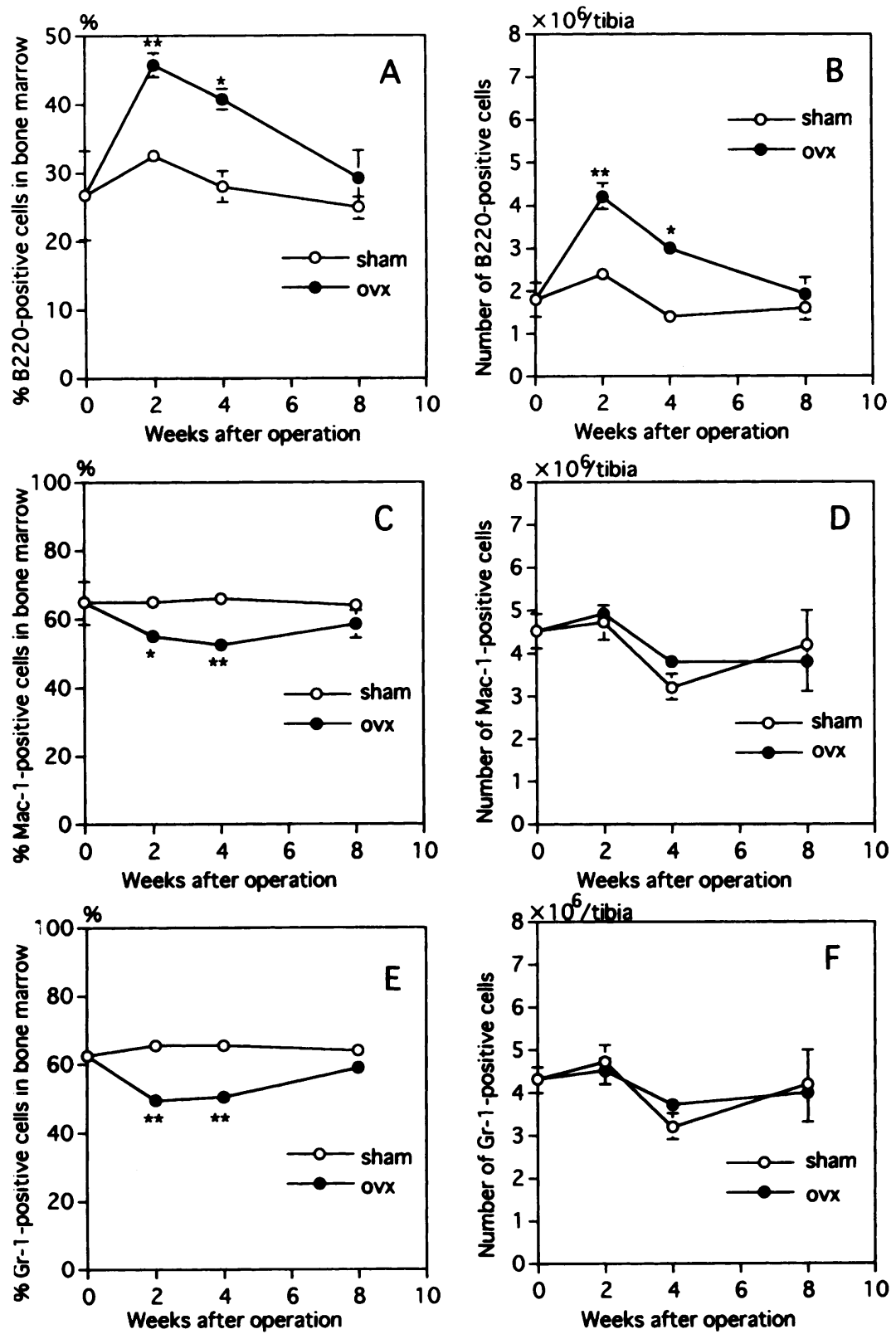

Figure 2. Time course of changes in the percentage and the number of B220-, Mac-1-, or Gr-1-positive cells in bone marrow collected from sham-operated $(O)$ and OVX (•) mice. Bone marrow cells were stained with B220 ( $A$ and $B$ ), Mac-1 $(C$ and $D)$ or Gr-1 $(E$ and $F$ ), and analyzed by a flow cytometer. The percentage of B220- $(A)$, Mac-1- $(C)$, and Gr1- $(E)$ positive cells was measured, and the number of B220- $(B)$, Mac-1- $(D)$, and Gr-1- $(F)$ positive cells per tibia was calculated from the percentage of positive cells and the number of nucleated marrow cells per tibia. Significantly different from sham mice: **, $P<0.001 ; *, P<0.01$. Data are expressed as the means \pm SEM of $8-19$ animals.

marked increase in bone marrow cells, and the stimulation of hemopoiesis was due to the specific accumulation of $B$ lymphocyte precursors which expressed B220 $0^{\text {low }} \cdot \mu$-negative phenotype. Administration of estrogen restored it. Furthermore, the in vitro growth and differentiation of B lymphocytes were inhibited by adding estrogen. Very recently, Medina et al. (19) reported that B lymphopoiesis in murine bone marrow was suppressed during pregnancy. They also showed that estrogen selectively suppressed B lymphocyte precursors when given to normal female mice. Therefore, the present study using OVX mice confirms the previous findings reported by Medina et al. (19) in pregnant mice. These observations suggest that estrogen is an important regulatory factor for hemopoiesis, especially of B cell lineage.

In OVX mice, the decreased level of serum estrogen was still retained at $8 \mathrm{wk}$ after operation, but all of the changes in marrow hemopoiesis returned to normal at this time point. It is unlikely that the restoration of hemopoiesis is due to the sys- temic compensation of estrogen synthesized by extragonadal tissues such as adrenals. Previous studies have indicated that aromatase, which catalyzes the aromatization of androgen for estrogen synthesis, is present in bone marrow cells and osteoblastic cells $(26,27)$. This suggests the possibility that estrogen locally produced in bone marrow is capable of acting as a local regulator for hemopoiesis. Further studies are needed to prove this hypothesis.

It is well established that stromal cells play a key role in hemopoiesis in bone marrow (3-5). Previous studies have shown that bone marrow stromal cells support the development of B lymphocytes from hemopoietic precursor cells, and that the support of B cell differentiation is mediated at least in part by specific soluble factors $(4,28,29)$. Namen et al. (30) reported the molecular cloning of cDNA encoding such a factor, which is now known as IL-7. IL-7 is an essential factor for the ability of stromal cells to support B lymphopoiesis. Previous studies 

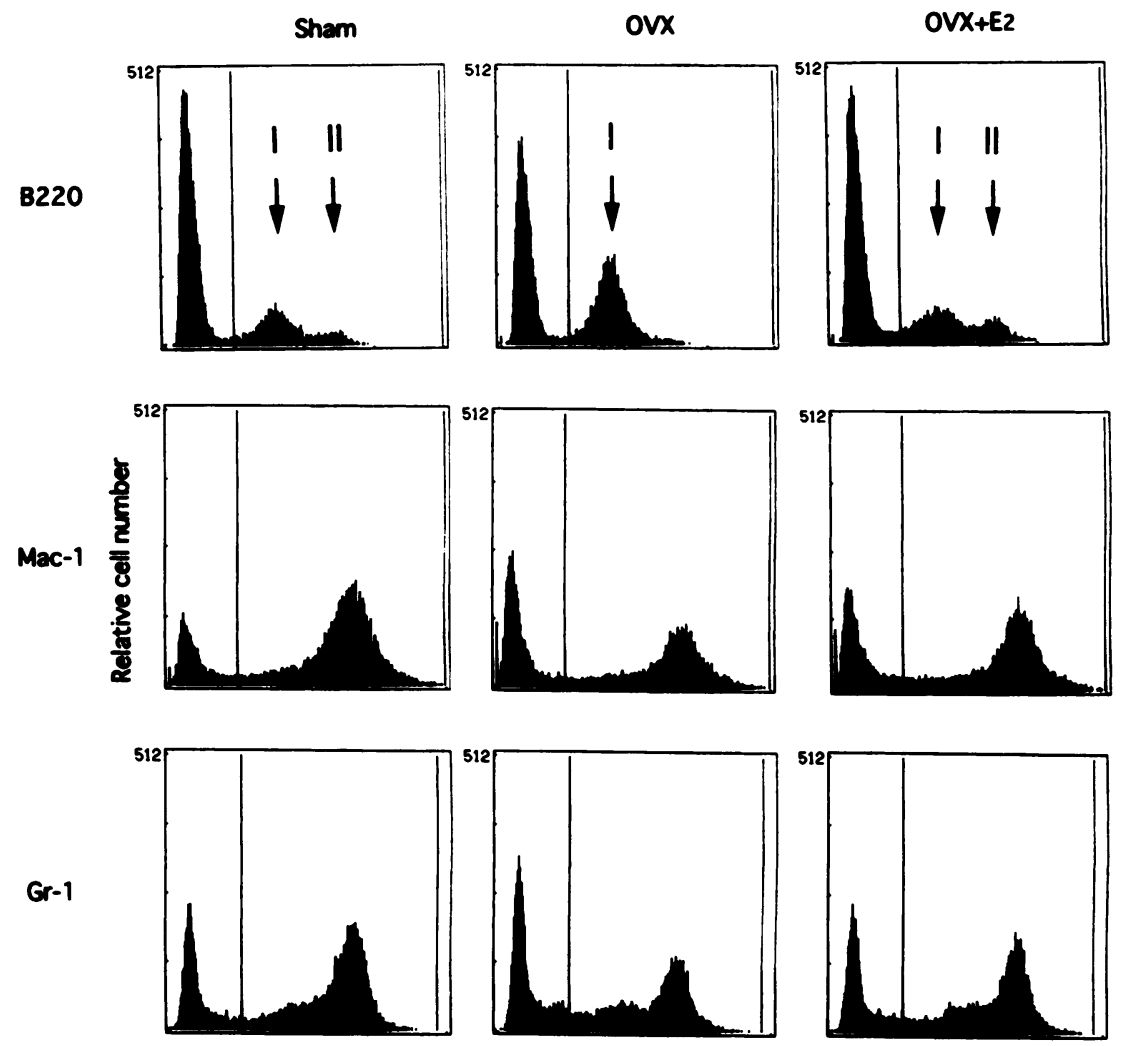

$\log$ fluorescence intensity
Figure 3. Differential patterns of B220-, Mac-1-, or Gr-1-positive cells in bone marrow collected from sham-operated (left), OVX (middle), and OVX mice treated with estrogen (right). Bone marrow cells were collected 2 wk after surgery, and stained with the respective antibodies. For estrogen treatment, OVX mice were given a pellet of $17 \beta$-estradiol $(10 \mu \mathrm{g})$ immediately after surgery. B220-positive cells from sham-operated mice were classified into two subpopulations, peak I $\left(B 220^{\text {low }}\right)$ and peak II (B220 $\left.{ }^{\text {high }}\right)$. The percentage of B220-positive cells; sham: $27.8 \%$, OVX: $45.5 \%, \mathrm{OVX}+\mathrm{E}_{2}: 30.8 \%$. The number of $\mathrm{B} 220$ positive cells; sham: $2.0 \times 10^{6} /$ tibia, OVX: 4.3 $\times 10^{6} /$ tibia, OVX $+\mathrm{E}_{2}: 2.4 \times 10^{6} / \mathrm{tibia}$. The percentage of Mac-1-positive cells; sham: $69.6 \%$, OVX: $56.2 \%$, OVX $+\mathrm{E}_{2}: 65.2 \%$. The number of Mac-1-positive cells; sham: $5.2 \times 10^{6} / \mathrm{tibia}, \mathrm{OVX}$; $5.3 \times 10^{6} /$ tibia, OVX $+\mathrm{E}_{2}: 5.2 \times 10^{6} /$ tibia. The percentage of Gr-1-positive cells; sham: $66.5 \%$, OVX: $56.4 \%$, OVX $+\mathrm{E}_{2}: \mathbf{6 8 . 5 \%}$. The number of Gr-1-positive cells; sham: $4.9 \times 10^{6} /$ tibia, OVX: $5.3 \times 10^{6} /$ tibia, OVX $+\mathrm{E}_{2}: 5.4 \times 10^{6} /$ tibia. have also suggested that the stromal cell-dependent B cell development requires a set of several factors expressed on stromal cells. For example, certain adhesion molecules such as c-kit, CD44 and very late antigen-4 (VLA-4) are thought to be essential for B cell differentiation, in particular in the early stage of B cell development $(9,31,32)$.

This study demonstrated that estrogen deficiency stimulates B lymphopoiesis and accumulates B lymphocyte precursors which express $\mathrm{B} 220^{\text {low }} \cdot \mu$-negative in bone marrow. To examine the effects of estrogen on B lymphopoiesis in vitro, we cocultured ST2 and bone marrow cells. Previous studies have demonstrated that ST2 cells produce not only the adhesion molecules necessary for B cell development at an early stage but also IL-7 necessary at a later stage $(4,33,34)$. Therefore, hemopoietic precursor cells can grow and differentiate into B cells on an ST2 cell layer. In this co-culture system, estrogen highly suppressed the generation of B lymphocytes (Fig. 6). When estrogen was added to the co-culture, B cell precursors could not grow on the ST2 cell layer on days 5-7, and B cell colonies were not formed on ST2 cells on days 10-14. It has been reported that bone marrow stromal cells possess specific receptors for estrogen and that estrogen modulates the production of cytokines by stromal cells (14). These results suggest that estrogen modulates some factors expressed on stromal cells, and suppresses the ability of stromal cells to support B lymphopoiesis. It is also possible that the suppression of B lymphopoiesis is due to the direct effect of estrogen on B lymphocyte precursors. At present, it is difficult to conclude which possibility is correct.

Several lines of evidence have suggested that there is an interaction between sex hormones and the immune system. Women are more inclined to suffer from various autoimmune diseases than men. For example, lupus erythematosus is more prevalent in females than in males, and estrogen administration accelerates the disease process $(35,36)$. Rheumatoid arthritis is also more prevalent in women than in men (37). Another example is the longer period required for the tissue rejection response in females (38). Castration shortens skin graft rejection time, suggesting that a deficiency of sex steroids activates the cellmediated immune response (39). Estrogen administration induces atrophy of the thymus, resulting in immunosuppression. This indicates that estrogen suppresses the growth and differentiation of $T$ lymphocytes in the thymus $(18,40)$. The increase in circulating sex steroids during pregnancy also induces a transient involution of the thymus and suppresseses immunoresponses, which may be involved in preventing the maternal-fetal rejection response $(41,42)$. On the other hand, OVX results in hyperplasia of peripheral lymph nodes, spleen, and thymus (42). These observations indicate that estrogen suppresses the growth and function of T lymphocytes. Previous studies have shown that estrogen receptors are detectable in the reticular stromal cells of the thymus but not in thymocytes $(40,43)$. This suggests that estrogen suppresses $\mathrm{T}$ lymphopoiesis by modulating functions of stromal cells in thymus.

Recent studies in bone cell biology have suggested the association of bone metabolism with the hemopoietic system. An estrogen deficiency induced by OVX increases bone turnover, resulting in bone loss by stimulated osteoclastic bone resorption. Osteoclast progenitors are thought to be derived from hemopoietic precursor cells in bone marrow $(1,44)$. Several cytokines 
A

Sham

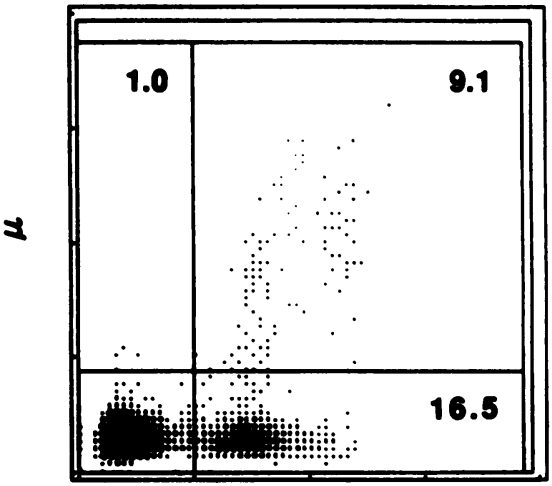

B220 ovx

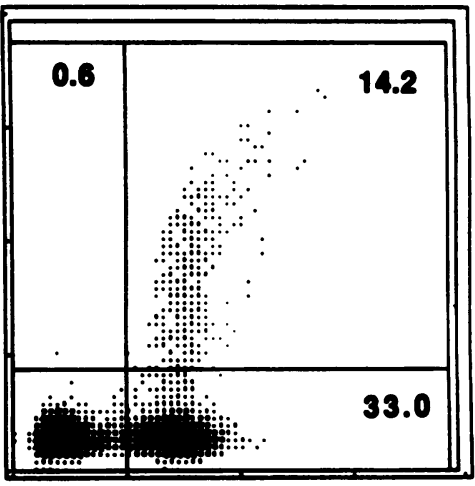

B220

B

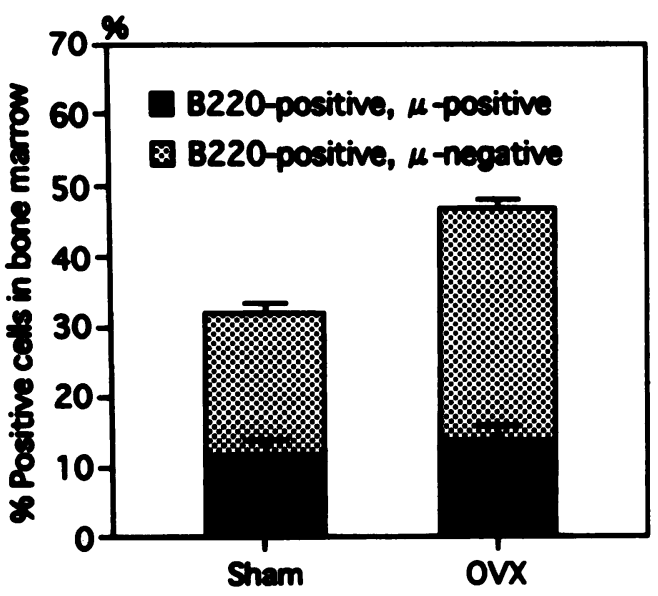

involved in hemopoiesis and immune response are involved in the regulation of bone metabolism. For example, M-CSF is essential for osteoclastic bone resorption. Mice homozygous for the recessive mutation of osteopetrosis (op) on chromosome 3, op/op mice, have an abnormal hemopoietic microenvironment. They also lack mature macrophages and osteoclasts (45). Yoshida et al. (46) have reported that the abnormal hemopoiesis and the failure of bone resorption in op/op mice are due to a defect in M-CSF production caused by a single base pair inser-
Figure 4. Two-color immunofluorescence analysis of B220 and $\mu$ chain of IgM in bone marrow cells collected from sham-operated and OVX mice. $(A)$ Respective typical patterns from 5 sham and 5 OVX animals are shown. $(B)$ The percentage of subpopulations of B220-positive cells; B220-positive $\cdot \mu$-positive ( $(\square)$ and B220-positive $\cdot \mu$-negative (目), was calculated from the analysis shown in $A$. Data are expressed as the means\pm SEM of five animals. The number in each quadrant represents the percentage of the cells having each phenotype.

tion in the coding region of the M-CSF gene. Concurrent studies using recombinant $\mathrm{M}$-CSF have confirmed the importance of M-CSF in osteoclastic bone resorption $(2,12,47)$. IL-6 is also thought to be involved in both hemopoiesis and bone resorption (15-17). Recently we showed that IL-6 stimulated osteoclast development in the presence of soluble IL-6 receptors and that factors such as IL-11, oncostatin M, and leukemia inhibitory factor, all of which exert their functions through gp130 (the signal-transducing chain of IL-6 receptor), also induced osteo-

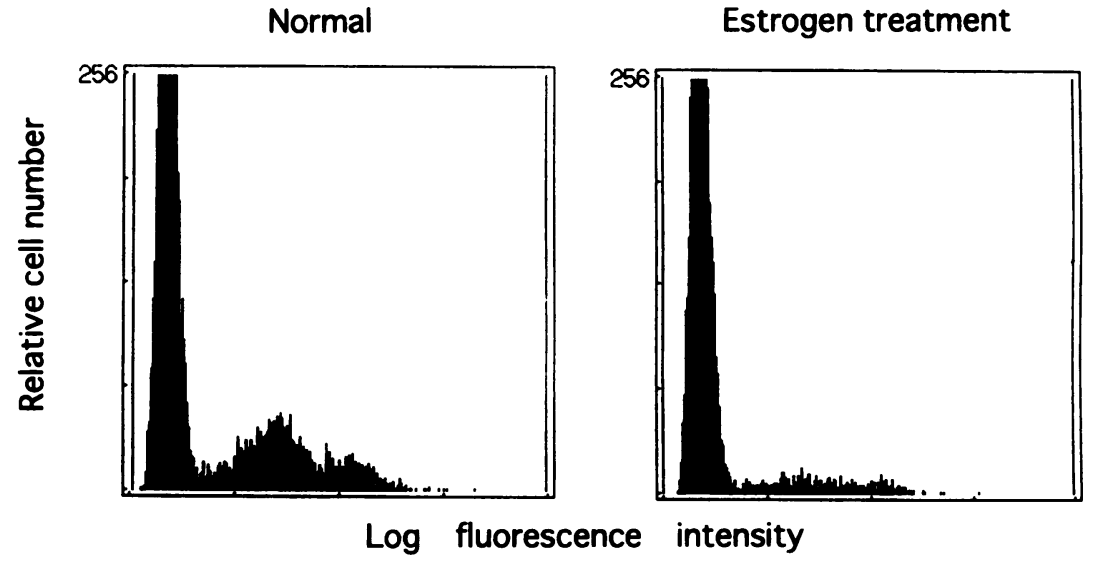

Figure 5. The effects of estrogen on B lymphopoiesis in bone marrow of normal mice. Female mice were given a slow-releasing pellet $(10 \mu \mathrm{g})$ of $17 \beta$ estradiol. $1 \mathrm{wk}$ later, bone marrow cells from normal mice and those treated with estrogen, were stained with B220 antibody and analyzed by flow cytometry. The results were highly reproducible in three separate analyses. A representative data is shown. Percentages of B220-positive cells: normal mice; $22.5 \pm 3.4 \%(n=3)$, those treated with estrogen; $12.7 \pm 2.2 \%(n=3)$. 
A

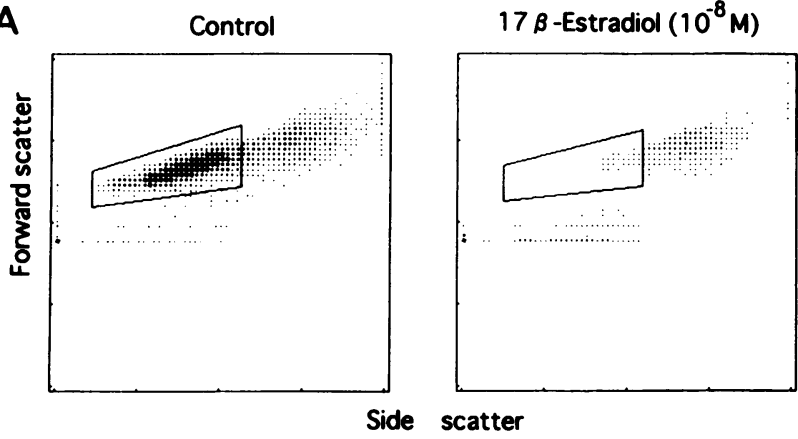

B

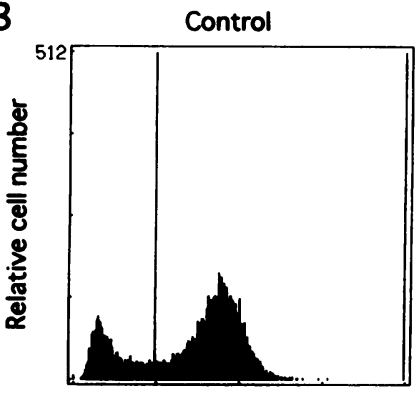

Fluorescence

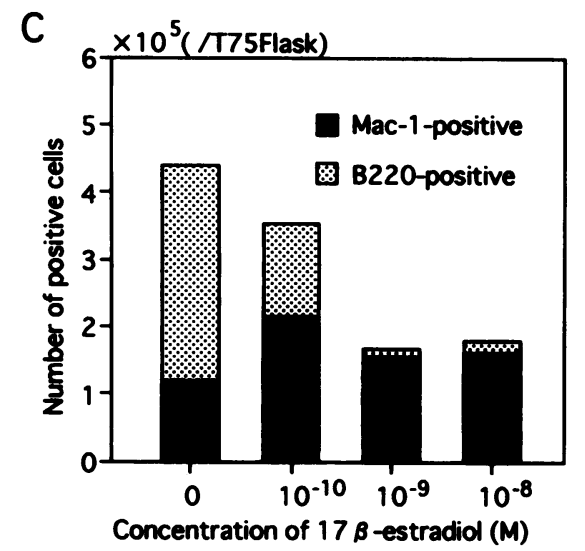

Figure 6. Effect of $17 \beta$-estradiol on the growth and differentiation of B lymphocytes in vitro. ST2 cells were preincubated with or without $10^{-10}-10^{-8} \mathrm{M} 17 \beta$-estradiol for $7 \mathrm{~d}$, then co-cultured with bone marrow cells under the same conditions. 2 wk later, bone marrow cells grown on the ST2 layer were collected and analyzed by flow cytometry using B220 and Mac-1 antibodies. ( $A$ ) The forward and side scatter pattern in the control culture (left) and in that incubated with $10^{-8} \mathrm{M} 17 \beta$ estradiol (right). The area enclosed by a trapezium represents the lymphocytes. (B) Pattern of B220-positive cells in the area shown in $A$. The percentages of B220-positive cells were 73\% in the control culture and $30 \%$ in that incubated with $10^{-8} \mathrm{M} 17 \beta$-estradiol. $(C)$ The number of B220- (घ) and Mac-1- ( $\square$ ) positive cells was calculated from the percentage of positive cells and the number of bone marrow cells collected from each culture flask. The results were highly reproducible in four separate experiments. A representative data is shown.

clast formation (17). Most of these cytokines are produced by stromal cells in bone marrow. Girasole et al. (14) have reported that estrogen suppresses IL- 6 production by bone marrow stromal cells in vitro. Jilka et al. (48) have reported that the increase in osteoclast development after OVX was inhibited by not only estrogen, but also by an antibody against IL-6 in vivo. These observations suggest that estrogen regulates both hemopoiesis and bone metabolism by suppressing cytokine synthesis by bone marrow stromal cells. B lymphopoiesis is also regulated by cytokines produced by stromal cells such as IL-7. Furthermore, both B lymphopoiesis and osteoclast development are supported by certain adhesion molecules expressed in marrow stromal cells. Further studies are needed to understand the role of estrogen in hemopoiesis and bone metabolism.

In conclusion, an estrogen deficiency induced by ovariectomy causes a marked increase in bone marrow cells. The stimulation of hemopoiesis is due to the specific accumulation of $\mathbf{B}$ lymphocyte precursors in bone marrow. The microenvironment supported by marrow stromal cells is thought to be important for B lymphopoiesis. The mechanism of the action of estrogen in B lymphopoiesis is of considerable interest and currently being explored in our laboratory.

\section{Acknowledgments}

We would like to thank Dr. T. Kina, Kyoto University, for kindly providing us TER 119 antibody, and Dr. M. Tomita, Showa University, for lending us a flow cytometer. We also thank Dr. N. Aoki, Mitsubishi BCL Co. Ltd., for measuring the levels of $17 \beta$-estradiol in mouse serum.

This work was supported by Grants-in-Aid (04404072 and 05671552) from the Ministry of Science, Education and Culture of Japan.

\section{References}

1. Mundy, G. R., and G. D. Roodman. 1987. Osteoclast ontogeny and function. Bone Miner. Res. 5:209-281.

2. Suda, T., N. Takahashi, and T. J. Martin. 1992. Modulation of osteoclast differentiation. Endocr. Rev. 13:66-80.

3. Kincade, P. W. 1987. Experimental models for understanding B lymphocyte formation. Adv. Immunol. 41:181-267.

4. Whitlock, C. A., G. F. Tidmarsh, C. Muller-Sieburg, and I. L. Weissman. 1987. Bone marrow stromal cell lines with lymphopoietic activity express high levels of a pre-B neoplasia-associated molecule. Cell. 48:1009-1021.

5. Ogawa, M., S. Nishikawa, K. Ikuta, F. Yamamura, M. Naito, K. Takahashi, and S. I. Nishikawa. 1988. B cell ontogeny in murine embryo studied by a culture system with the monolayer of a stromal cell clone, ST-2: B cell progenitor develops first in the embryonal body rather than in the yolk sac. EMBO (Eur. Mol. Biol. Organ.) J. 7:1337-1343.

6. Bernardi, P., V. P. Patel, and H. F. Lodish. 1987. Lymphoid precursor cells adhere to two different sites on fibronectin. J. Cell Biol. 105:489-498.

7. Campbell, A. D., M. W. Long, and M. S. Wicha. 1987. Haemonectin, a bone marrow adhesion protein specific for cells of granulocyte lineage. Nature (Lond.). 329:744-746.

8. Gordon, M. Y., D. Clarke, J. Atkinson, and M. F. Greaves. 1990. Hemopoietic progenitor cell binding to the stromal microinvironment in vitro. Exp. Hematol. 18:837-842.

9. Miyake, K., I. L. Weissman, J. S. Greenberger, and P. W. Kincade. 1991. Evidence for a role of the integrin VLA-4 in lympho-hemopoiesis. J. Exp. Med. 173:599-607.

10. Udagawa, N., N. Takahashi, T. Akatsu, H. Tanaka, T. Sasaki, T. Nishihara, T. Koga, T. J. Martin, and T. Suda. 1990. Origin of osteoclast: mature monocytes and macrophages are capable of differentiating into osteoclasts under a suitable microenvironment prepared by bone marrow-derived stromal cells. Proc. Natl. Acad. Sci. USA. 87:7260-7264.

11. Udagawa, N., N. Takahashi, T. Akatsu, T. Sasaki, A. Yamaguchi, H. Kodama, T. J. Martin, and T. Suda. 1989. The bone marrow-derived stromal cell lines MC3T3-G2/PA6 and ST2 support osteoclast-like cell differentiation in cocultures with mouse spleen cells. Endocrinology. 125:1805-1813.

12. Tanaka, S., N. Takahashi, N. Udagawa, T. Tamura, T. Akatsu, E. R. Stanley, T. Kurokawa, and T. Suda. 1993. Macrophage colony-stimulating factor is indispensable for both proliferation and differentiation of osteoclast progenitors. J. Clin. Invest. 91:257-263.

13. Pacifici, R., C. Brown, E. Puscheck, E. Friederick, R. McCracken, D. Maggio, E. Slatopolsky, and L. V. Avioli. 1991. Effect of surgical menopause and estrogen replacement on cytokine release from human blood mononuclear cells. Proc. Natl. Acad. Sci. USA. 88:5134-5138.

14. Girasole, G., R. L. Jilka, G. Passeri, S. Boswell, G. Boder, D. C. Williams, 
and S. C. Manolagas. 1992. 17 $\beta$-Estradiol inhibits interleukin-6 production by bone marrow-derived stromal cells and osteoblasts in vitro: a potential mechanism for the antiosteoporotic effect of estrogens. J. Clin. Invest. 89:883-891.

15. Ishimi, Y., C. Miyaura, C. H. Jin, T. Akatsu, E. Abe, Y. Nakamura, A Yamaguchi, S. Yoshiki, T. Matsuda, T. Hirano, T. Kishimoto, and T. Suda. 1990. IL-6 is produced by osteoblasts and induces bone resorption. J. Immunol. 145:3297-3303.

16. Kurihara, N., D. Bertolini, T. Suda, Y. Akiyama, and G. D. Roodman. 1990. IL-6 stimulates osteoclast-like multinucleated cell formation in long term human marrow cultures by inducing IL-1 release. J. Immunol. 144:4226-4230.

17. Tamura, T., N. Udagawa, N. Takahashi, C. Miyaura, S. Tanaka, Y. Koishihara, Y. Ohsugi, K. Kumaki, T. Taga, T. Kishimoto, and T. Suda. 1993. Soluble interleukin-6 receptor triggers osteoclast formation by interleukin-6. Proc. Natl. Acad. Sci. USA. 90:11924-11928.

18. Screpanti, I., S. Morrone, D. Meco, A. Santoni, A. Gulino, R. Paolini, A Crisanti, B. J. Mathieson, and L. Frati. 1989. Steroid sensitivity of thymocyte subpopulations during intrathymic differentiation. Effects of $17 \beta$-estradiol and dexamethasone on subsets expressing $\mathrm{T}$ cell antigen receptor or $\mathrm{IL}-2$ receptor. $J$. Immunol. 142:3378-3383.

19. Medina, K. L., G. Smithson, and P. W. Kincade. 1993. Suppression of B lymphopoiesis during normal pregnancy. J. Exp. Med. 178:1507-1515.

20. Coffman, R. L. 1986. Surface antigen expression and immunoglobulin gene rearrangement during mouse pre-B cell development. Immunol. Rev. 69:523.

21. Spangrude, G. J., S. Heimfeld, and I. L. Weissman. 1988. Purification and characterization of mouse hematopoietic stem cells. Science (Wash. DC). 241:58 62.

22. Springer, T., G. Galfre., D. S. Secher, and C. Milstein. 1979. Mac-1: a macrophage differentiation antigen identified by monoclonal antibody. Eur. J. Immunol. 9:301-306.

23. Ikuta, K., T. Kina, I. MacNeil, N. Uchida, B. Peault, Y-H. Chein, and I. L. Weissman. 1990. A development switch in thymic lymphocyte maturation potential occurs at the level of hematopoietic stem cells. Cell. 62:863-874.

24. Nishikawa, S. I., M. Ogawa, S. Nishikawa, T. Kunisada, and H. Kodama. 1988. B lymphopoiesis on stromal cell clone: stromal cell clones acting on different stages of B cell differentiation. Eur. J. Immunol. 18:1767-1771.

25. Hardy, R. R., C. E. Carmack, S. A. Shinton, J. D. Kemp, and K. Hayakawa 1991. Resolution and characterization of pro-B and pre-pro-B cell stages in normal mouse bone marrow. J. Exp. Med. 173:1213-1225.

26. Frisch, R. E., J. A. Canick, and D. Tulchinsky. 1980 . Human fatty marrow aromatizes androgen to estrogen. J. Clin. Endocrinol. \& Metab. 51:394-396.

27. Purohit, A., A. M. Flanagan, and M. J. Reed. 1992. Estrogen synthesis by osteoblast cell lines. Endocrinology. 131:2027-2029.

28. Landreth, K., and K. Dorshkind. 1988. Pre-B cell generation potentiated by soluble factors from a bone marrow stromal cell line. J. Immunol. 140:845852 .

29. Namen, A. E., A. E. Schmierer, C. J. March, R. W. Overell, L. S. Park, D. L. Urdal, and D. Y. Mochizuki. 1988. B cell precursor growth-promoting activity. Purification and characterization of a growth factor active on lymphocyte precursors. J. Exp. Med. 167:988-1002.

30. Namen, A. E., S. Lupton, K. Hjerrild, J. Wignall, D. Mochizuki, A. E. Schmierer, B. Mosley, C. J. March, D. L. Urdal, S. Gillis, D. Cosman, and R. G. Goodwin. 1988. Stimulation of B-cell progenitors by cloned murine interleukin7. Nature (Lond.). 333:571-573.

31. Miyake, K., K. L. Medina, S. I. Hayashi, S. Ono, T. Hamaoka, and P. W.
Kincade. 1990. Monoclonal antibodies to Pgp-1/CD44 block lymphohemopoiesis in long-term bone marrow cultures. J. Exp. Med. 171:477-488.

32. Okada, S., H. Nakauchi, K. Nagayoshi, S. Nishikawa, S. I. Nishikawa, Y. Miura, and T. Suda. 1991. Enrichment and characterization of murine hematopoietic stem cells that express c-kit molecule. Blood. 1706-1712.

33. Sudo, T., M. Ito, Y. Ogawa, M. lizuka, H. Kodama, T. Kunisada, S. Hayashi, M. Ogawa, K. Sakai, S. Nishikawa, and S. I. Nishikawa. 1989. Interleukin-7 production and function in stromal cell-dependent B cell development. $J$. Exp. Med. 170:333-338.

34. Hayashi, S., T. Kunisada, M. Ogawa, T. Sudo, H. Kodama, T. Suda, S. Nishikawa, and S. I. Nishikawa. 1990. Stepwise progression of B lineage differentiation supported by interleukin 7 and other stromal cell molecules. J. Exp. Med. 171:1683-1695.

35. Roubinian, J. R., N. Talal, J. S. Greenspan, J. R. Goodman, and P. K. Siiteri. 1979. Delayed androgen treatment prolongs survival in murine lupus. $J$. Clin. Invest. 63:902-911.

36. Sakane, T., A. D. Steinberg, and I. Green. 1978. Studies of immune functions of patients with systemic lupus erythematosus. Arthritis Rheum. 21:657664.

37. Vandenbroncke, J. P., H. A. Valkenburg, J. W. Boersma, A. Cats, J. J. M. Festen, O. Huber-Bruning, and J. J. Rasker. 1982. Oral contraceptives and rheumatoid arthritis: Further evidence for a preventive effect. Lancet. II:839842.

38. Ablin, R. J., R. A. Bhatti, P. D. Guinan, and W. Khin. 1979. Modulatory effects of oestrogen on immunological responsiveness. Clin. Exp. Immunol. 38:83-91.

39. Graff, R. J., M. A. Lappe, and G. D. Snell. 1969. The influence of the gonads and adrenal glands on the immune response to skin grafts. Transplantation. 7:105-111.

40. Barr, I. G., B. A. K. Khalid, P. Pearce, B. H. Toh, P. F. Bartlett, R. G Scollay, and J. W. Funder. 1982. Dihydrotestosterone and estradiol deplete corticosensitive thymocytes lacking in receptors for these hormones. J. Immunol 128:2825-2828.

41. Bardawil, W. A., G. W. Mitchell, R. P. McKeogh, and D. J. Marchant. 1962. Behavior of skin homografts in human pregnancy. Am. J. Obstet. Gynecol. 84:1283-1299.

42. Grossman, C. J. 1985. Interactions between the gonadal steroids and the immune system. Science (Wash. DC). 227:257-261.

43. Thompson, E. A. 1981. The effects of estradiol upon the thymus of the sexually immature female mouse. J. Steroid Biochem. 14:167-174.

44. Nijweide, P. J., E. H. Burger, and J. H. M. Feyen. 1986. Cells of bone proliferation, differentiation, and hormonal regulation. Physiol. Rev. 66:855-886.

45. Wiktor-Jedrzejczak, W., A. Ahmed, C. Szczylik, and R. R. Skelly. 1982. Hematological characterization of congenital osteopetrosis in op/op mouse. Possible mechanism for abnormal macrophage differentiation. J. Exp. Med. 156:15161527.

46. Yoshida, H., S. Hayashi, T. Kunisada, M. Ogawa, S. Nishikawa, H. Okamura, T. Sudo, L. D. Shultz, and S. I. Nishikawa. 1990. The murine mutation osteopetrosis is in the coding region of the macrophage colony stimulating factor gene. Nature (Lond.). 345:442-444.

47. Kodama, H., A. Yamasaki, N. Nose, S. Niida, Y. Ohgame, M. Abe, M Kumegawa, and T. Suda. 1991. Congenital osteoclast deficiency in osteopetrotic (op/op) mice is cured by injections of macrophage colony-stimulating factor. $J$. Exp. Med. 173:269-272.

48. Jilka, R. L., G. Hangoc, G. Girasole, G. Passeri, D. C. Williams, J. S. Abrams, B. Boyce, H. Broxmeyer, and S. C. Manolagas. 1992. Increased osteoclast development after estrogen loss: Mediation by interleukin-6. Science (Wash DC). 257:88-91. 